\title{
Gender differences in the distal radial artery diameter for the snuffbox approach
}

\author{
Yongcheol Kim, Youngkeun Ahn, Min Chul Kim, Doo Sun Sim, \\ Young Joon Hong, Ju Han Kim, Myung Ho Jeong
}

Department of Cardiology, Chonnam National University Hospital, Gwangju, Republic of Korea

\begin{abstract}
Background: Recently, interventional cardiologists have been increasingly interested in snuffbox approach for coronary angiography $(C A G)$ and percutaneous coronary intervention (PCI). However, there is lack of data regarding distal radial artery $(R A)$ diameter according to gender. Therefore, the aim herein was to investigate gender differences in the diameter of distal RA diameter.

Methods: Left snuffbox approach was done in 117 patients who had planned CAG or PCI for suspected myocardial ischemia between 1 December 2017 and 28 February 2018 at the Chonnam National University Hospital, Gwangju, Korea. Left RA angiography was achieved from 101 patients. Among 101 individuals, 69 (68.3\%) men and 32 (31.7\%) women were enrolled. There was no significant difference in systolic and diastolic blood pressure, body mass index, left ventricular systolic function, or patients with acute coronary syndrome in either group.

Results: The average diameter of distal $R A$ was $2.57 \mathrm{~mm}$ in all patients. Women had a significantly smaller diameter of distal $R A$ than men $(2.40 \mathrm{~mm}$ vs. $2.65 \mathrm{~mm}, p=0.016)$. Nevertheless, CAG via snuffbox approach by 6 Fr sheath was successfully performed in all 117 patients. Regarding success rate of the distal RA approach, women had a lower success rate (32/38) compared with men (72/79), but not significantly $(84.2 \%$ vs. $91.1 \%, p=0.264)$.

Conclusions: Females has a significantly smaller distal RA diameter compared to males. Moreover, the success rate of the distal RA approach tends to be higher in men than in women. (Cardiol J 2018; 25, 5: 639-641)

Key words: distal radial artery, snuffbox approach, coronary angiography, percutaneous coronary intervention
\end{abstract}

\section{Introduction}

Recently, there has been an increasing interest in the distal radial artery (RA) approach, called the snuffbox approach, for coronary angiography (CAG) and percutaneous coronary intervention (PCI) among interventional cardiologists [1-6]. However, there is a lack of data regarding the difference in distal RA diameter according to gender. Furthermore, the success rate of snuffbox puncture and cannulation in males and females has as yet not been investigated. Therefore, the aim of this study was to evaluate gender differences in the distal RA diameter and success rate of the snuffbox approach for CAG and PCI.

\section{Methods}

In total, 117 patients who had well palpable pulse in the left snuffbox area were enrolled to undergo the snuffbox approach for CAG or PCI by a single radial operator between December 1 , 2017 and February 28, 2018 at Chonnam National University Hospital, Gwangju, Korea. Left RA

Address for correspondence: Dr. Youngkeun Ahn, MD, PhD, FACC, FSCAI, Department of Cardiology, Cardiovascular Center, Chonnam National University Hospital, 42 Jebong-ro, Dong-gu, Gwangju, 61469, Republic of Korea, tel: 82-62-220-4764, fax: 82-62-224-4764, e-mail: cecilyk@hanmail.net 


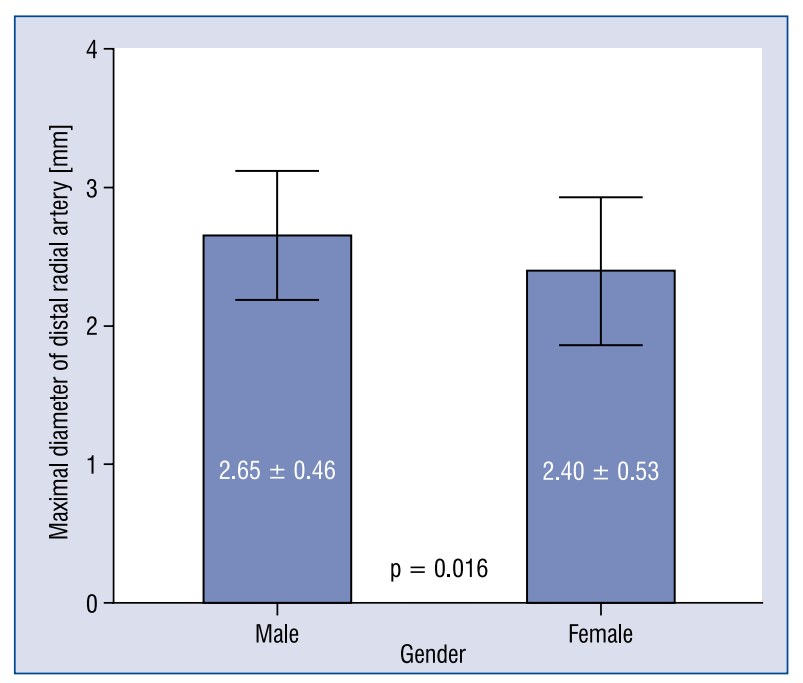

Figure 1. Gender differences in the distal radial artery diameter. Data expressed as mean \pm standard deviation.

angiography was performed in 101 patients. Detailed information regarding preparation of the left snuffbox approach and measurement of the diameter of the left distal RA has been described in a previous study [3]. This study was approved by the Institutional Review Board at Chonnam National University Hospital (approval number: 2018-192). Continuous variables including the diameter of the RA are expressed as mean with standard deviation and compared using the unpaired or paired t-test, as appropriate. Categorical variables including the success rate of the left snuffbox approach are expressed as numbers with percentages and was analyzed using the $\chi^{2}$ test.

\section{Results}

Of the 101 individuals with left RA angiography, 69 (68.3\%, mean age of $63.1 \pm 11.0$ years) were male and $32(31.7 \%$, mean age of $71.0 \pm 8.4$ years) were female. There were no significant differences in systolic and diastolic blood pressure, body mass index, left ventricular systolic function, neither were there patients with acute coronary syndrome in either of the two groups. The average left distal RA diameter was $2.57 \pm 0.50 \mathrm{~mm}$. The female group had a significantly smaller distal RA diameter than the male group $(2.40 \pm 0.53 \mathrm{~mm}$ vs. $2.65 \pm 0.46 \mathrm{~mm}, \mathrm{p}=0.016$ ) (Fig. 1).

The left snuffbox approach was attempted without a preprocedural patency test, such as the Allen test or Barbeau test in 117 patients. Baseline

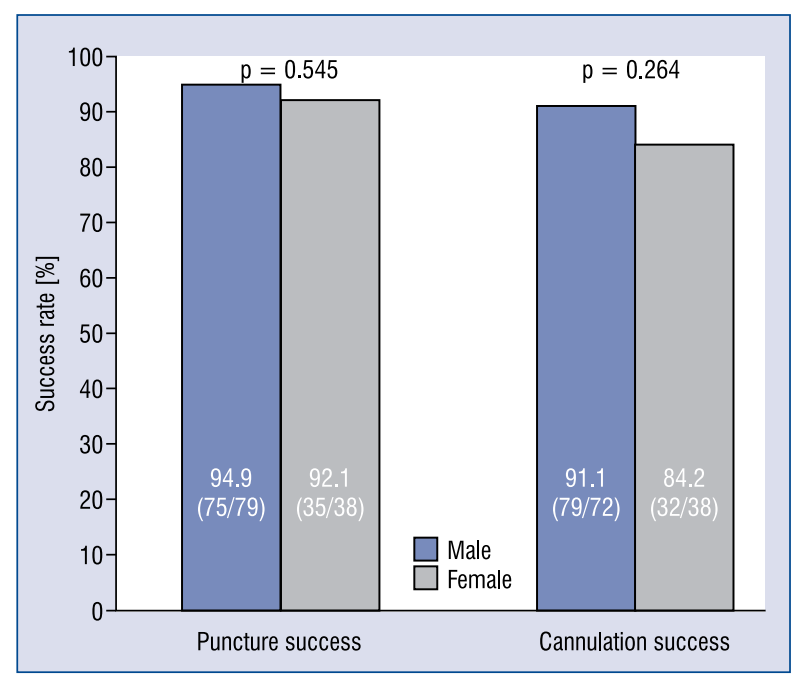

Figure 2. Success rate of the left snuffbox approach in the male and female groups.

characteristics of the study population are shown in Table 1. The overall success rate of snuffbox puncture and cannulation was $94.0 \%(\mathrm{n}=110)$ and $88.9 \%(\mathrm{n}=104)$, respectively. CAG was performed via the right conventional radial approach if the snuffbox approach failed. Regarding the success rate of the snuffbox approach according to gender and the puncture success rate showed no significant difference between the two groups $(92.1 \%$ [35/38] in the female group vs. $94.9 \%$ [75/79] in the male group, $\mathrm{p}=0.545$ ). Moreover, the female group had a lower success rate of snuffbox cannulation than the male group, as defined by successful insertion of the radial sheath via the distal RA; however, the difference was not significant $(84.2 \%$ [32/38] vs. $91.1 \%$ [72/79], $\mathrm{p}=0.264$; Fig. 2). However, CAG via the left snuffbox approach was performed in all 104 patients who underwent successful snuffbox cannulation using a 6-French sheath (Radifocus ${ }^{\circledR}$ Introducer II, Terumo Corporation, Tokyo, Japan). With regard to vascular complications, 2 cases $(1.9 \%, 1$ in a male and 1 in a female) of forearm swelling with bruising, not requiring surgery or transfusion, were observed. During the study period, PCI via the left snuffbox approach was performed in 33 patients including 23 men and 10 women. All 33 patients successfully underwent PCI via the left snuffbox approach with a 6-French sheath and there was no case requiring a change in vascular access to the femoral or conventional radial approach. Albeit vessel spasms were not specifically investigated, it was not encountered during the procedures in this study. 
Table 1. Baseline characteristics of the study population.

\begin{tabular}{lccccc}
\hline Variables & $\begin{array}{c}\text { Total } \\
\text { patients } \\
(\mathbf{n}=\mathbf{1 1 7})\end{array}$ & $\begin{array}{c}\text { Cannulation } \\
\text { success group } \\
(\mathbf{n}=104)\end{array}$ & $\begin{array}{c}\text { Failed } \\
\text { group } \\
(\mathbf{n}=13)\end{array}$ & $\begin{array}{c}\text { Men in the } \\
\text { success group } \\
(\mathbf{n}=\mathbf{7 2})\end{array}$ & $\begin{array}{c}\text { Women in the } \\
\text { success group } \\
(\mathbf{n}=32)\end{array}$ \\
\hline Age [years] & $65.6 \pm 11.1$ & $65.5 \pm 11.1$ & $66.1 \pm 11.0$ & $63.0 \pm 11.3$ & $71.0 \pm 8.4$ \\
Male & $79(67.5 \%)$ & $72(69.2 \%)$ & $7(53.8 \%)$ & - & - \\
Female & $38(32.5 \%)$ & $32(30.8 \%)$ & $6(46.2 \%)$ & - & - \\
NSTE-ACS & $45(38.5 \%)$ & $44(42.3 \%)$ & $1(16.7 \%)$ & $29(40.3 \%)$ & $15(46.9 \%)$ \\
STEMI & $3(2.6 \%)$ & $2(1.9 \%)$ & $1(16.7 \%)$ & $2(2.8 \%)$ & $0(0 \%)$ \\
LVEF [\%] & $61.0 \pm 10.9$ & $61.1 \pm 11.0$ & $60.2 \pm 10.5$ & $60.8 \pm 10.0$ & $61.6 \pm 13.2$ \\
ESRD & $6(5.1 \%)$ & $6(5.8 \%)$ & $0(0 \%)$ & $5(6.9 \%)$ & $1(3.1 \%)$ \\
\hline
\end{tabular}

Data expressed as number (\%) or mean \pm standard deviation.

ESRD - end-stage renal disease; LVEF — left ventricular ejection fraction; NSTE-ACS — non-ST-segment elevation acute coronary syndrome; STEMI - ST-segment elevation acute myocardial infarction

\section{Discussion}

According to available research, this is the first study reporting a comparison of distal RA diameter according to gender. Performing CAG or $\mathrm{PCI}$ via the conventional radial approach in women is considered technically more challenging because of an increased rate of RA spasm and smaller RAs [7-9]. In the present subgroup analysis, the female group showed a significantly smaller conventional RA diameter than the male group $(2.55 \pm 0.50 \mathrm{~mm}$ vs. $2.80 \pm 0.48 \mathrm{~mm}, \mathrm{p}=0.019$ ). This tendency was also observed in the distal RA in the current study. Nevertheless, access site crossover from the left snuffbox approach to another access route was not required in any patient after successful cannulation during $\mathrm{CAG}$ or PCI. Although the number of patients was too small to determine the reason for this observation, less tortuosity of the left subclavian trunk might be one of the factors for absence of access site failure.

There were several limitations in this study. First, this was a retrospective single-center study with a small number of patients. Second, all snuffbox approaches were performed only via the left distal RAs and by a single operator. These factors might have led to selection bias.

\section{Conclusions}

Women have a significantly smaller distal RA diameter than men. Moreover, the success rate of the distal RA approach tends to be higher in men than women. Therefore, male patients would be more suited to an inexperienced distal radial operator when the left snuffbox approach is planned. Regarding the success rate of the procedures via the left snuffbox approach, once cannulation was successful, CAG or PCI via the snuffbox approach of the left RA appears to have a success rate comparable to conventional radial access. Prospective studies are needed to further confirm safety and efficacy of the snuffbox approach.

\section{Acknowledgements}

The authors would like to thank all colleagues in the cardiac catheterization laboratories at Chonnam National University Hospital for their contribution to this study.

\section{Conflict of interest: None declared}

\section{References}

1. Kiemeneij F. Left distal transradial access in the anatomical snuffbox for coronary angiography (ldTRA) and interventions (ldTRI). EuroIntervention. 2017; 13(7): 851-857, doi: 10.4244/EIJ-D-17-00079, indexed in Pubmed: 28506941.

2. Valsecchi O, Vassileva A, Cereda AF, et al. Early clinical experience with right and left distal transradial access in the anatomical snuffbox in 52 consecutive patients. J Invasive Cardiol. 2018; 30(6): 218-223, indexed in Pubmed: 29543187.

Kim Y, Ahn Y, Kim I, et al. Feasibility of coronary angiography and percutaneous coronary intervention via left snuffbox approach. Korean Circ J. 2018 [Epub ahead of print], doi: 10.4070/kcj.2018.0181, indexed in Pubmed: 30088362 .

4. Kim Y, Jeong MH, Kim I, et al. Intravascular ultrasound-guided percutaneous coronary intervention with drug-eluting stent for unprotected left main disease via left snuffbox approach. Korean Circ J. 2018; 48(6): 532-533, doi: 10.4070/ /kcj.2018.0016, indexed in Pubmed: 29856149.

5. Berezhnoi K, Kokov L, Vanyukov A, Kim Y. Complete revascularization via left snuffbox approach in a nonagenarian patient with acute myocardial infarction. Cardiol J. 2018; 25(4): 530-531, doi: 10.5603/CJ.2018.0083, indexed in Pubmed: 30211930.

6. Kim Y, Jeong MH, Berezhnoi K, et al. Recannulation of distal radial artery for steged procedure after successful primary percutaneous coronary intervention. J Invasive Cardiol. 2018;30(10): E105-E106.

7. Pandie S, Mehta SR, Cantor WJ, et al. Radial versus femoral access for coronary angiography/intervention in women with acute coronary syndromes: insights from the RIVAL trial (radial vs femorAL access for coronary intervention). JACC Cardiovasc Interv. 2015; 8(4): 505-512, doi: 10.1016/j. jcin.2014.11.017, indexed in Pubmed: 25907080.

8. Abazid RM, Smettei OA, Mohamed MZ, et al. Radial artery ultrasound predicts the success of transradial coronary angiography. Cardiol J. 2017; 24(1): 9-14, doi: 10.5603/CJ.a2016.0072, indexed in Pubmed: 27665851.

9. Buturak A, Gorgulu S, Norgaz T, et al. The long-term incidence and predictors of radial artery occlusion following a transradial coronary procedure. Cardiol J. 2014; 21(4): 350-356, doi: 10.5603/CJ.a2013.0128, indexed in Pubmed: 24142678 . 